\title{
The potential value of seasonal forecasts in a changing climate in southern Africa
}

\author{
H. C. Winsemius ${ }^{1}$, E. Dutra ${ }^{2}$, F. A. Engelbrecht ${ }^{3,4}$, E. Archer Van Garderen ${ }^{3,4}$, F. Wetterhall ${ }^{2}$, F. Pappenberger ${ }^{2,6}$, and \\ M. G. F. Werner ${ }^{1,5}$ \\ ${ }^{1}$ Deltares, P.O. Box 177, $2600 \mathrm{MH}$, Delft, the Netherlands \\ ${ }^{2}$ European Centre for Medium-Range Weather Forecasts, Reading, UK \\ ${ }^{3}$ Council for Scientific and Industrial Research, Auckland Park, South Africa \\ ${ }^{4}$ School of Geography, Archaeology and Environmental Sciences, University of the Witwatersrand, \\ Johannesburg, South Africa \\ ${ }^{5}$ College of Hydrology and Water Resources, Hohai University, Nanjing, China
}

Correspondence to: H. C. Winsemius (hessel.winsemius@deltares.nl)

Received: 30 September 2013 - Published in Hydrol. Earth Syst. Sci. Discuss.: 4 December 2013

Revised: 22 October 2013 - Accepted: 5 March 2014 - Published: 25 April 2014

\begin{abstract}
Subsistence farming in southern Africa is vulnerable to extreme weather conditions. The yield of rain-fed agriculture depends largely on rainfall-related factors such as total seasonal rainfall, anomalous onsets and lengths of the rainy season and the frequency of occurrence of dry spells. Livestock, in turn, may be seriously impacted by climatic stress with, for example, exceptionally hot days, affecting condition, reproduction, vulnerability to pests and pathogens and, ultimately, morbidity and mortality. Climate change may affect the frequency and severity of extreme weather conditions, impacting on the success of subsistence farming. A potentially interesting adaptation measure comprises the timely forecasting and warning of such extreme events, combined with mitigation measures that allow farmers to prepare for the event occurring. This paper investigates how the frequency of extreme events may change in the future due to climate change over southern Africa and, in more detail, the Limpopo Basin using a set of climate change projections from several regional climate model downscalings based on an extreme climate scenario. Furthermore, the paper assesses the predictability of these indicators by seasonal meteorological forecasts of the European Centre for Medium-Range Weather Forecasts (ECMWF) seasonal forecasting system. The focus is on the frequency of dry spells as well as the frequency of heat stress conditions expressed in the temperature heat index. In areas where their frequency of occurrence increases in the future and predictability is found, seasonal
\end{abstract}

forecasts will gain importance in the future, as they can more often lead to informed decision-making to implement mitigation measures. The multi-model climate projections suggest that the frequency of dry spells is not likely to increase substantially, whereas there is a clear and coherent signal among the models of an increase in the frequency of heat stress conditions by the end of the century. The skill analysis of the seasonal forecast system demonstrates that there is a potential to adapt to this change by utilizing the weather forecasts, given that both indicators can be skilfully predicted for the December-February season, at least 2 months ahead of the wet season. This is particularly the case for predicting above-normal and below-normal conditions. The frequency of heat stress conditions shows better predictability than the frequency of dry spells. Although results are promising for end users on the ground, forecasts alone are insufficient to ensure appropriate response. Sufficient support for appropriate measures must be in place, and forecasts must be communicated in a context-specific, accessible and understandable format.

\section{Introduction}

Southern Africa is largely a semi-arid region, experiencing substantial inter- and intra-annual climate variability (Barron et al., 2003; Nyakudya and Stroosnijder, 2011). This 
variability expresses itself both in rainfall and temperature and frequently causes negative impacts on agricultural activities, which are often of a smallholder nature and reliant on limited resources. Throughout Sub-Saharan Africa, 95\% of cultivated land is under rain-fed agriculture (Parr et al., 1990; Rockström, 2003). Given the limited extent and scope for development of surface water irrigation, most countries in southern African rely strongly on rain-fed agriculture (Wetterhall et al., 2014). Therefore, precipitation patterns, timings and amounts are directly correlated to crop yield and indirectly to food security and resilience to climate variability. While a lower total amount of rainfall over the crop growing season will influence the crop yield, it is often the poor distribution of rainfall resulting in dry spells and wet spells that is the cause for reduced crop yields (Barron and Okwach, 2005; Ingram et al., 2002; Ochola and Kerkides, 2003; Rockström, 2000). In particular, maize (Zea mays L.) is sensitive to the occurrence of dry spells as well as insufficient rain for seedlings (due to too-early planting) (Barron et al., 2003; Nyakudya and Stroosnijder, 2011). Given the typical length of the growing season for maize (120-140 days) and the relatively short rainy season across large parts of southern Africa, maize is considered a particularly vulnerable crop if it is grown on rain-fed farms. Dairy and other livestock farming may further suffer seriously from climate change (Archer van Garderen, 2011). Dairy production remains fairly stable under a range of climate conditions, but reduces up to $20 \%$ with increasing heat stress above a threshold (Ravagnolo et al., 2000). Heat stress is caused by the combined effects of dry bulb temperature, humidity, solar radiation and wind speed (Dikmen and Hansen, 2009). When a hot period ends, the productivity does not necessary return to normal values immediately (Ravagnolo et al., 2000). The drop in productivity is generally proportional to the length of the hot period.

Current variability in climate may already cause substantial reductions in agricultural yields. There is concern that climate change may aggravate the effects of this variability, due to decreases or more erratic rainfall as well as an overall increase in temperature, leading to more frequent occurrence of livestock heat stress conditions (Archer van Garderen, 2011; Davis, 2011; Hetem et al., 2011; Kusangaya et al., 2013; Nardone et al., 2010; Nesamvuni et al., 2012; Ziervogel et al., 2014). These changes may make the agricultural sector throughout southern Africa vulnerable. As a consequence, the importance of forecasting, warning and strengthening of preparedness (Carsell et al., 2004) to mitigate the effects of negatively impacting climate variability may increase. This requires (1) adequate skill of such forecasts to detect critical weather conditions for the agricultural sector; and (2) that sufficient mitigation measures for response are in place. Reducing the impact of dry spells on the yield may be achieved through local mitigation measures such as rainwater harvesting techniques (Brown and Hansen, 2008), or temporary supplementary irrigation from, for example, on-farm ponds
(Barron and Okwach, 2005). Predictions of dry spells across the growing season, and in particular during the periods most sensitive to the impact of dry spells, help to plan such mitigation measures and optimize the use of a scarce commodity such as water stored in on-farm ponds. Prediction of heat stress conditions aids farmers in deciding upon the planning of anti-heat stress measures such as additional water points, sprinkling, reduced handling (e.g. transportation or moving camps), setting up of shaded areas, as well as specialized attention to vulnerable herd groups (Ravagnolo et al., 2000).

The importance of predictability of indicators, which are tailored to specific end users such as rain-fed agriculture, is acknowledged by Reason et al. (2005). They investigated the inter-annual variability of dry spells within the rainy season and anomalies in the onset of rainy seasons over the Limpopo Basin. Reason et al. (2005) found a significant relationship between these indicators and Niño 3.4 sea surface temperature (SST). They suggest that within the Limpopo region, predictability of the rainfall characteristics at the seasonal scale may exist. This was further investigated by Wetterhall et al. (2014), who showed that with the proper treatment of forecast data, skilful predictions of rainfall characteristics can be found across the Limpopo region. In addition, ambient temperature, required to estimate potential heat stress, shows seasonal predictability in the southern African region using SST according to Barnston and Smith (1996). Particularly during the rainy season, the predictability is very high, and is not even very strongly dependent on lead time. However, seasonal predictions need to be transformed into meaningful indicators for end users, to be useful to inform decisions in planning cropping patterns, planting period, and heat stress relieving measures.

In this paper we investigate whether critical weather conditions for subsistence farming in southern Africa are likely to increase in a changing climate, and if so, whether current seasonal forecasts are good enough to detect them skilfully. If this is the case, then the importance of seasonal forecasts will increase in the future, because planning of timely mitigation actions will be needed more frequently. Throughout this study, we assume that the skill of seasonal forecast systems will not change in the future and that farmers will be able to access and interpret forecast information in time. We emphasize that forecasting is only one adaptation measure. Other adaptation measures (possibly in addition to forecasting) may be required to fully adapt to climate change, such as shifting of agricultural practices to other crop types or cattle, improved farming methods and improved water availability (e.g. through reservoir construction and operations). Critical weather conditions are expressed as indicators with defined thresholds that are meaningful for end-user decision-making. We apply here two indicators: (1) frequency of dry spells of a defined minimum length and (2) frequency of days with heat stress conditions expressed in the temperature heat index (THI) above a defined threshold. Note that if other adaptation measures besides forecasting are considered, this does 
not mean that forecasting is not useful anymore. It is likely that the threshold at which a critical condition occurs (and therefore the forecast threshold at which a mitigation action is needed) will shift and that a combination of forecasting and other measures will lead to successful adaptation. In this paper, we only focus on forecasting as a possible adaptation measure. First this paper describes whether the frequency of these critical conditions changes according to regional climate model (RCM) simulations. In addition, the skill of seasonal forecasts in reproducing the frequency of the indicators and thresholds across the rainy season is estimated. In Sect. 2 we outline the methodology, Sect. 3 describes the results of our study, which are further discussed in light of the importance of forecasts in a changing climate in Sect. 4. In this section, we also discuss limitations of our study. We conclude our paper in Sect. 5.

\section{Methods}

\subsection{Area and time period of study}

This study focuses on southern Africa (lat -35 to $-10^{\circ}$, long from 10 to $55^{\circ}$ ), and in particular the Limpopo River basin. The Limpopo Basin is shared by four countries; namely Botswana, South Africa, Zimbabwe and Mozambique, and is an area widely acknowledged to have critically stressed access to water (LIMCOM, 2010). While data availability and compatibility between the four countries to produce basin estimates remains a challenge (LIMCOM, 2010), regular food security and vulnerability estimates are made by the Regional Vulnerability Assessment Committee (RVAC). They provide cereal production and livestock production outlooks for the four basin member countries, as part of the southern African Development Community (SADC). For example, for the 2011/2012 season, the cereal surplus/deficit was indicated as $-356,-856,-3522$, and $-834 \mathrm{kt}$ (kilotonnes) for Botswana, Mozambique, South Africa and Zimbabwe respectively (RVAC, 2011); while livestock production for beef for the whole of mainland SADC from 2006 through 2010 increased from 1.25 to 1.45 million tons (RVAC, 2011).

The rainy season and therefore also the cropping season in the Limpopo is concentrated in the months of December, January and February (DJF). Planting usually starts in November, but it was decided to focus on DJF since this provides an additional month of lead time to consider in this study. The precipitation is highly variable in terms of total amount, onset and intermittency (Engelbrecht et al., 2013; Kane, 2009; Love et al., 2010; Reason et al., 2005; Usman and Reason, 2004). DJF is also the season with the highest temperatures and therefore the highest probability of livestock heat stress conditions. We therefore focus our analysis on the DJF season.

\subsection{Data used}

\subsubsection{Seasonal forecasts}

Seasonal forecasts provide information on the development of the climate up to 6 to 12 months ahead of time rather than detailed day-by-day variations. Probabilistic seasonal forecast systems have significantly more skill than deterministic forecasts (Molteni et al., 2011), and such probabilistic information can be used by end users in support of decisionmaking (see O'brien, 2002; Ramos et al., 2010, 2013). In this study we use the ECMWF (European Centre for MediumRange Weather Forecasts) System 4 seasonal forecast system (Molteni et al., 2011), based on an atmosphere-ocean coupled model, which has been operational since November 2011. The atmospheric model has a horizontal resolution of about $79 \mathrm{~km}$ with 91 vertical levels, and the ocean model has a horizontal resolution of approximately $1^{\circ}$ with 42 vertical levels. The seasonal forecasts consist of a 51 member ensemble with 7 months lead time, including the month of issue, referred to as 0 month lead time. S4 has a set of reforecasts (or hindcasts) starting on the first of every month for the period January 1981 to December 2010. The hindcast set is provided for calibration purposes with the same configuration as the operational forecasts, except in the ensemble size: 51 members for the initial forecast dates of February, May, August, and November; and 15 members for the remaining initial forecast dates. Molteni et al. (2011) present an overview of S4 model biases and forecast performance. Dutra et al. $(2013,2014)$ and Mwangi et al. (2014) evaluated the $\mathrm{S} 4$ in terms of meteorological droughts in several African basins and areas.

Mwangi et al. (2014) conclude that ECMWF seasonal forecasts add value to the statistical forecasts currently in operations at the Horn of Africa.

\subsubsection{ERA Interim reanalysis}

The ECMWF reanalysis ERA-Interim (Dee et al., 2011), which has been available since 1979, was used in this study to verify the skill of the seasonal forecasts. The atmospheric model has the same resolution as the seasonal forecasts (about $79 \mathrm{~km}$ ) and is associated with a 4D-var data assimilation scheme for the optimal consistency between globally available observations and model background. The $2 \mathrm{~m}$ temperature and dew point temperature (used in this study to derive relative humidity) are analysed over land separately from the main atmospheric analysis. An optimal interpolation scheme produces 6-hourly estimates of $2 \mathrm{~m}$ temperature and dew point temperature, combining synoptic observations with background estimates derived from the latest atmospheric analysis. Therefore, over densely observed areas, ERAI $2 \mathrm{~m}$ temperature and dew point temperature can be considered close to observations. On the other hand, precipitation is a forecast product generated by the atmospheric 
model. This can lead to significant biases in ERAI precipitation (from daily to inter-annual scales). Dutra et al. (2013) show that over South Africa, and in particular the Limpopo Basin, ERAI monthly precipitation has good agreement with observations in terms of intensity and inter-annual variability. On daily timescales, Belo-Pereira et al. (2011) found a reasonable performance of ERAI over the Iberian Peninsula, despite an overestimation of wet days (excessive drizzle).

\subsubsection{Bias corrected conformal-cubic atmospheric model simulations}

An ensemble of regional projections of future climate change over southern Africa, obtained using the conformal-cubic atmospheric model (CCAM), are examined in this paper. The variables from the projections used in this study are daily precipitation, daily maximum temperature and daily relative humidity. CCAM is a variable-resolution global atmospheric model, developed by the Commonwealth Scientific and Industrial Research Organisation (CSIRO) in Australia (McGregor and Dix, 2008; McGregor, 2005). When applied in stretched-grid mode, the model provides a flexible and computationally efficient way of downscaling coupled global climate model (CGCM) projections to high resolution over an area of interest. The projections described here were obtained by downscaling the simulations of six CGCM projections reported in Assessment Report Four (AR4) and the Coupled Model Intercomparison Project Phase 3 (CMIP3) to high resolution over southern and tropical Africa. All six CGCM projections are for the period 1961-2100, and for the A2 emission scenario of the Special Report on Emission Scenarios (SRES). The A2 scenario represents the most extreme emission scenario. The bias-corrected sea surface temperatures (SSTs) and sea ice concentrations of the CGCM projections were first used to force CCAM simulations at a quasi-uniform horizontal resolution of about $200 \mathrm{~km}$. These simulations were subsequently applied for the nudging of high-resolution (about $60 \mathrm{~km}$ ) simulations over southern and tropical Africa. Detailed descriptions of the CGCMs used can be found in Malherbe et al. (2013). The CCAM downscaling procedure over Africa is described in more detail by Engelbrecht et al. (2011). The model's ability to simulate the present-day characteristics of regional climate has earlier been investigated rigorously over southern Africa (Engelbrecht et al., 2009, 2013; Landman et al., 2009) and for various other climatological regions (e.g. Lal et al., 2008; Nunez and McGregor, 2007).

To reduce systematic differences between present-day climate and model-simulated present-day climate, a simple monthly-scale mean bias-correction procedure was applied in this research, using the CRU TS3.1 data set of the Climatic Research Unit (CRU, Mitchell and Jones, 2005) as reference climate. Precipitation has been corrected with a multiplicative correction factor, while all other variables have been corrected with an additive correction. In particular, precipitation may be an uncertain variable in climate change projections. To derive changes in frequency of occurrence of critical weather conditions, we therefore compare current and future conditions, as derived from CCAM rather than comparing future conditions from CCAM with current conditions from an observational data set or reanalysis data set.

\subsection{Selection and definition of indicators and thresholds}

In this study, we analyse the forecasts as well as the severity of climate change by the frequency of occurrence of a defined critical condition. The critical conditions are expressed in an indicator, along with a threshold that measures the intensity of the event. Both indicator and threshold are selected so that they are meaningful for end users and cover the two most important agricultural activities in the basin:

- Dry spells: rain-fed agriculture is particularly vulnerable for dry spells within the growing season. While a lower total amount of rainfall during the crop growing season will influence the yield, it is more often the erratic temporal distribution of rainfall resulting in dry and wet spells that is the cause for both reduced crop yields or failure (Barron et al., 2003; Ochola and Kerkides, 2003; Usman and Reason, 2004). Both the frequency of occurrence of such dry spells and their length are important. We compute a dry spell by transforming the rainfall time series into a two-state time series (0: wet day, 1: dry day) (Barron et al., 2003; Groen and Savenije, 2006) and counting lengths of consecutive dry days within the DJF season. A dry day is given when rainfall is below $1 \mathrm{~mm}$ per day. We assume that $1 \mathrm{~mm}$ per day evaporates as interception or bare soil evaporation and does not take part in the plant production process (Gerrits et al., 2007; Groen and Savenije, 2006; Savenije, 2004). As thresholds, we have selected dry period durations of 3,5 and 10 days, which are in the order of the length, potentially causing reduced crop productivity (see e.g. Barron et al., 2003). The exact threshold causing potential loss in productivity is dependent on factors such as crop type, soil type and conditions, and crop growing stage. The threshold should therefore be selected on a case-bycase basis if an operational forecasting system is to be established. Since the indicator is of a non-continuous nature (i.e. a number of days), the amount of possible values for the frequency of spells in a given period of time reduces significantly with the threshold chosen (i.e. the theoretical maximum frequency of occurrence of a 15-day dry spell within 1 month is by default 2). Therefore the estimation of the climatology of the frequency of occurrence of dry spells longer than 10 days is compromised by the fact that too few unique values can be expected within the distribution. Dry periods longer than 10 days are therefore not considered for analysis here. 
- Temperature heat index (THI): THI is an empirical, unitless measurement and is a function of temperature and air humidity. The THI can be used as a measure for livestock heat stress, resulting in a serious decline in milk production/water use ratios. In this paper, THI is computed following the formulation of Dikmen and Hansen (2009):

$I_{\mathrm{TH}}=\left(c_{1} T+c_{2}\right)-c_{3}(1-H)\left(c_{1} T-c_{4}\right)$,

where $I_{\mathrm{TH}}$ is the THI [-], $T$ is the ambient temperature $\left[{ }^{\circ} \mathrm{C}\right], H$ is the ambient relative humidity $[-]$ and $c_{1}$ to $c_{4}$ are empirically derived constants with the respective values $1.8^{\circ} \mathrm{C}^{-1}, 32,0.55^{\circ} \mathrm{C}^{-1}$ and 26.8 . As thresholds, we selected a THI of 72 as an indicator for mild stress, and 78 as an indicator of severe stress (Nesamvuni et al., 2012; Ravagnolo et al., 2000). We applied Eq. (1) using the maximum ambient temperature on each day.

In future studies, more indicators could be included that affect different decisions, such as the onset of the rainy season, length of the rainy season, total seasonal rainfall and heat wave duration.

\subsection{Data analysis}

To estimate trends in changes in the frequency of occurrence of the chosen indicator and threshold combinations, we established climatologies for different indicator/threshold combinations over the full DJF season. These climatologies were derived over the following 40-year periods: 1961-2000, 2011-2050, 2061-2100. The derivation of a climatology has been done with the following steps:

- First we established a daily time series over the period of interest (e.g. 1961-2000) of the two indicators using precipitation for the two-state dry or wet days transformation, and temperature and relative humidity for the estimation of THI.

- Then we estimated for each DJF season within the period of interest a count of the amount of occurrences of the indicator/threshold combinations. This yields for each cell in the simulated grid extent 40 values, one for each year of the period of interest.

- Based on the 40 values, a climatological distribution of the indicator/threshold combination is established. The distribution is expressed in the form of selected quantiles. Because the amount of samples (40) is limited, samples of the 8 neighbouring cells of each cell under consideration are also included to build up the climatology distribution. This results in a sample size of $40 \times 9=360$ samples per cell.

We investigate whether the climatology of the DJF indicator/threshold combinations shows a significant increase in the frequency of occurrence, compared to the natural variability. If this is the case, then it becomes more important to have a skilful seasonal forecast.

The skill of the ECMWF S4 seasonal forecasts was assessed over the hindcast period (1981-2010) taking ERAI as verification, and following the same methodology for the indicators/threshold calculations as described before for the climate simulations. Three different scores were used to assess skill: correlation, relative operating characteristics (ROC) and reliability (REL) diagrams. The correlation is a deterministic score (only considering the ensemble mean), while ROC and REL evaluate probabilistic categorical forecasts. The score uncertainties due to temporal sampling were assessed by performing 1000 bootstrap samples. The details of the score calculations and bootstrapping methodology are available in the Supplement (Sect. S2.1).

\section{Results}

In the following two sections, the effect of climate change on dry spell and heat stress frequency is presented, along with the skill of the current seasonal forecasts in predicting these conditions.

\subsection{Effect of climate change on dry spell and heat stress frequency}

To demonstrate how climate change affects the chosen indicator/threshold combinations, we show the 30th and 70th percentiles of the distribution of the chosen indicator/threshold combinations. Figure 1 shows the changes in the distribution of the DJF frequency of occurrence of dry spells longer than 5 days over the time slices 1961-2000, 2011-2050 and 2061-2100 for all 6 climate projections. We show the 5-day threshold, because of the issue with reducing amounts of unique values for frequency of occurrence of dry spells with long durations (3-day and 10-day thresholds are shown in Figs. S1 and S2 in the Supplement). The percentile values do not change significantly over the different time slices, and are clearly smaller than the current climate variability (Fig. 1a-d). We therefore cannot conclude from the RCM projections that the frequency of dry spells will increase in the future.

In Fig. 2, the changes in distribution of the DJF frequency of days with THI higher than 78 are given. The variability in the current climate is not very large, but the climate scenarios project a considerable change by the end of the century. In fact, as mentioned earlier, dairy cattle stress is known to be severe with THI $>78$ (Nesamvuni et al., 2012; Ravagnolo et al., 2000) and according to these results, such conditions are now largely restricted to the lower valleys as well as the Kalahari Desert, but are likely to increase seriously in frequency towards 2100 across most countries north of South Africa (including the northern parts of South Africa itself). 

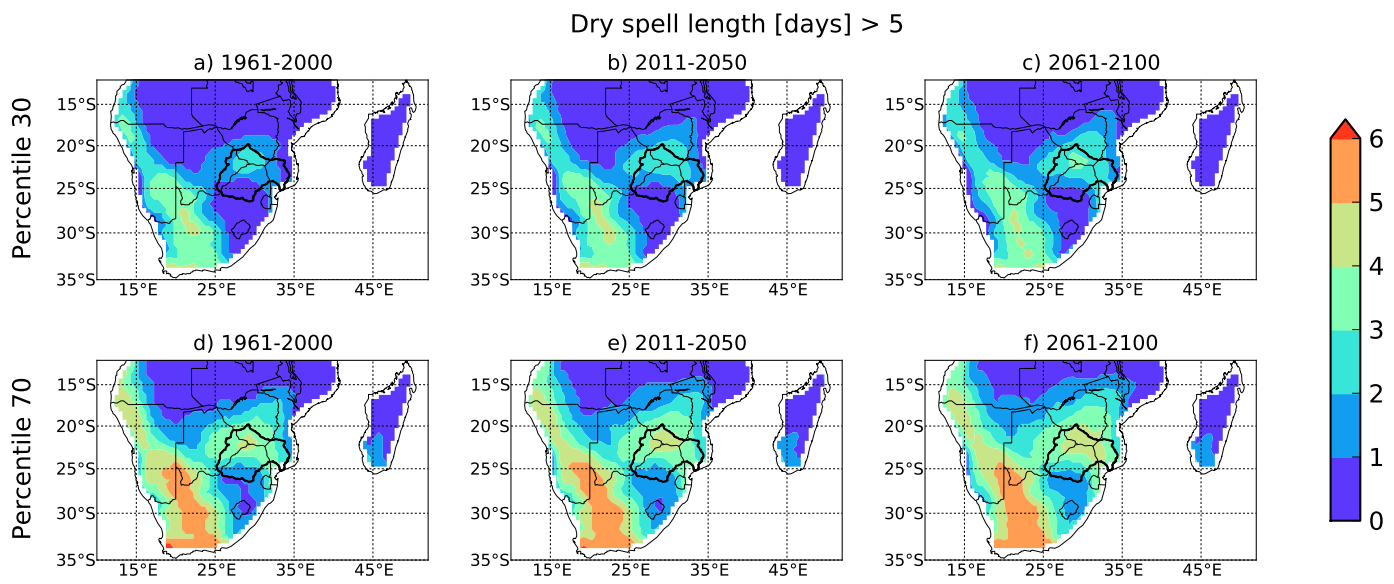

Fig. 1. Changes in the climatology of DJF frequency of occurrence of dry spells longer than 5 days. (a)-(c) show the 30th percentile. (d)(f) show the 70th percentile. From left to right panels, the changes in dry-spell frequency climatology are shown along different time slices in the RCM runs (1961-2000, 2011-2050 and 2061-2100).
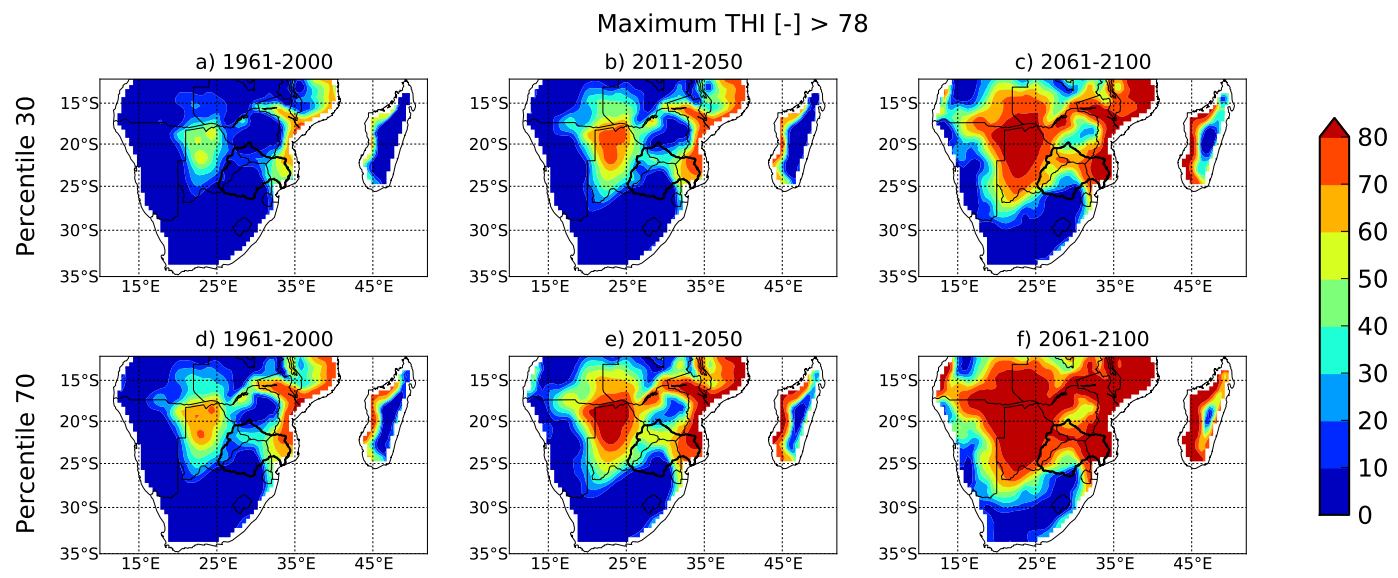

Fig. 2. Same as Fig. 1 but for changes in the climatology of DJF frequency of occurrence of days with THI higher than 78.

Similar increases are in the frequency of occurrence of THI larger than 72 and 84 (see Figs. S5 and S6 in the Supplement). According to these results, THI above 84 is now very rare across the studied region, but will occur quite frequently in the future over the Kalahari Desert, as well as the lower Zambezi Basin. THI exceedances of this type would stress most livestock, clearly a significant concern for these areas.

Figure 3 shows the spatial average of the changes in distributions of both the DJF 5-day dry spell frequency (a) and the frequency of THI above 78 (b), averaged over the Limpopo Basin. The six individual RCM projections indicate only a very small increase (in particular compared to the current climate variability) in the amount of dry spells from now until the end of the 21 st century. THI above 78 indicates a clear increase in frequency, far larger than the natural climate variability. The individual climate runs are also quite consistent, showing a relatively small variability in the projected change amongst the climate runs. In fact, this result demonstrates that if the IPCC A2 scenario becomes reality, on average an increase of a factor 3 to 4 of the amount of days with severe heat stress in the DJF season is to be expected, leading to an amount of about 60 days of heat stress during belownormal conditions (percentile 30) and about 70 during abovenormal conditions (percentile 70). This accounts for about $70 \%$ of all days within the DJF season compared to about $20 \%$ (20 days) in the current climate. These results can also be confirmed for the other THI thresholds (not shown here, but presented in Figs. S7 and S8 in the Supplement).

\subsection{Seasonal forecast of dry spell and heat stress frequency}

\subsubsection{Climatology of the indicator-threshold combinations}

Following a similar approach to the climate change analysis, the DJF 30th and 70th percentiles climatology of the frequency of dry spells of at least 5 days, and number of days 

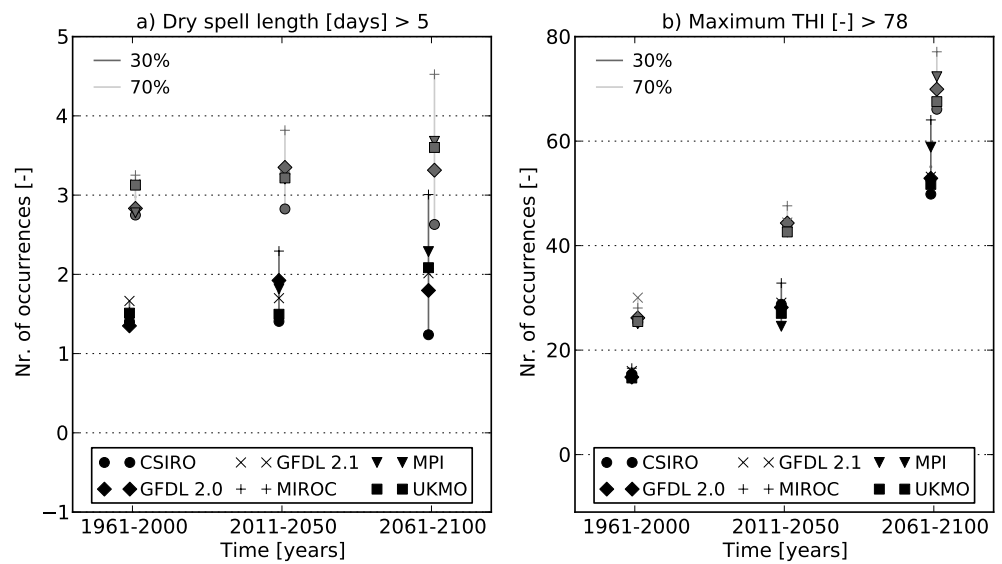

Fig. 3. Limpopo Basin-averaged changes in climatology from 1961-2000 to 2011-2050 to 2061-2100, of DJF frequency of occurrence of dry spells longer than 5 days according to the 6 RCM projections. The dark symbols denote the 30th percentile. The grey symbols denote the 70th percentile. The dark lines indicate the multi-model range for the 30th percentile. The grey lines indicate the multi-model range for the 70 th percentile.

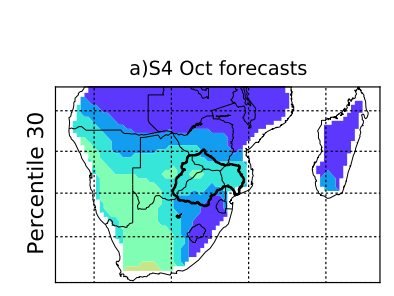

e)S4 Oct forecasts

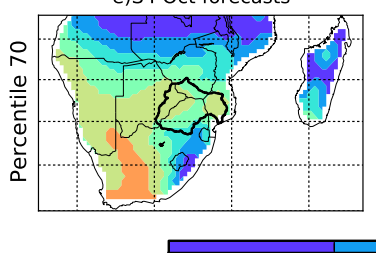

0

DJF \# 5 days DrySpells

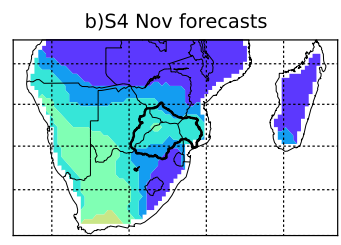

f)S4 Nov forecasts

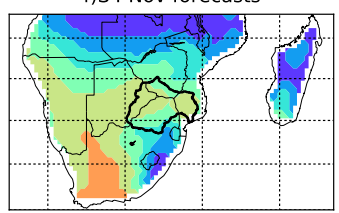

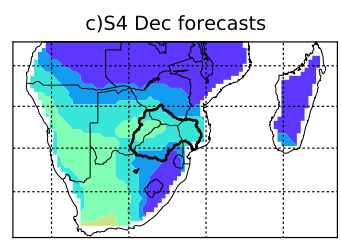

g)S4 Dec forecasts

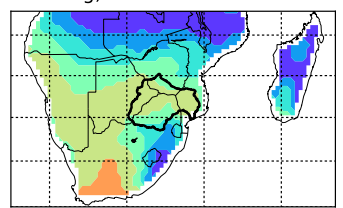

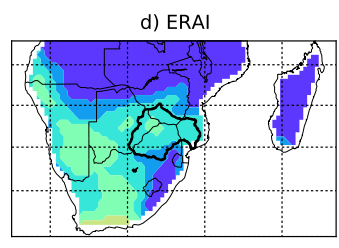

h) ERAI

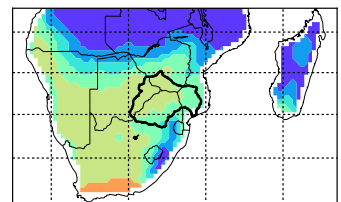

3 6

Fig. 4. Climatology of the DJF frequency of occurrence for 5-day dry spells. (a)-(d) show the 30th percentile and (e)-(h) the 70th percentile. From left to right ECMWF S4 forecasts initialized in October $(\mathbf{a}, \mathbf{e})$, November $(\mathbf{b}, \mathbf{f})$ and December $(\mathbf{c}, \mathbf{g})$ and from ERA-Interim $(\mathbf{d}, \mathbf{h})$.

with THI above 78 were compared for different S4 forecast initial dates and ERAI over the period 1981-2010. There is a reasonable agreement (in terms of spatial patterns and intensity) between S4 and ERAI climatologies of the frequency of dry spells of at least 5 days (Fig. 4). For the number of days with THI above 78, the S4 climatology displays a pronounced underestimation when compared with ERAI and a "cold" drift (lower THI) with lead time (panels a, b, c compared with panel $\mathrm{d}$ and panels e, $\mathrm{f}, \mathrm{g}$ compared with panel $\mathrm{h}$ in Fig. 5). This drift is likely to be associated with changes in sea surface temperature with lead time in the coupled atmosphere-ocean model. This confirms that the forecasts should be disseminated as anomalies, rather than absolute values. The skill assessment is therefore also set up in this way. The comparison between S4 and ERAI mean frequency of the indicators over the Limpopo Basin in Fig. 6 further supports these results.
The year-to-year variability of the climate simulations for the current climate cannot be directly compared with ERAI or S4. However, the time series of the Limpopo averages in Fig. 6 show similar mean values and inter-annual variability between the RCMs and ERAI and S4. In fact, the RCMs do not exhibit the "cold" bias in THI as seen in S4 (Fig. 6b), due to the bias correction applied to the climate simulations output (see Sect. 2.2). Figure 6 also displays the projected time evolution of the indicators for the period 2079-2100. There is a considerable increase in the number of days with THI above 78 , while there is no clear difference in the frequency of dry spells of at least 5 days. Similar results were found for the frequency of dry spells of at least 3 days and number of days with THI above 72 (see Supplement). 


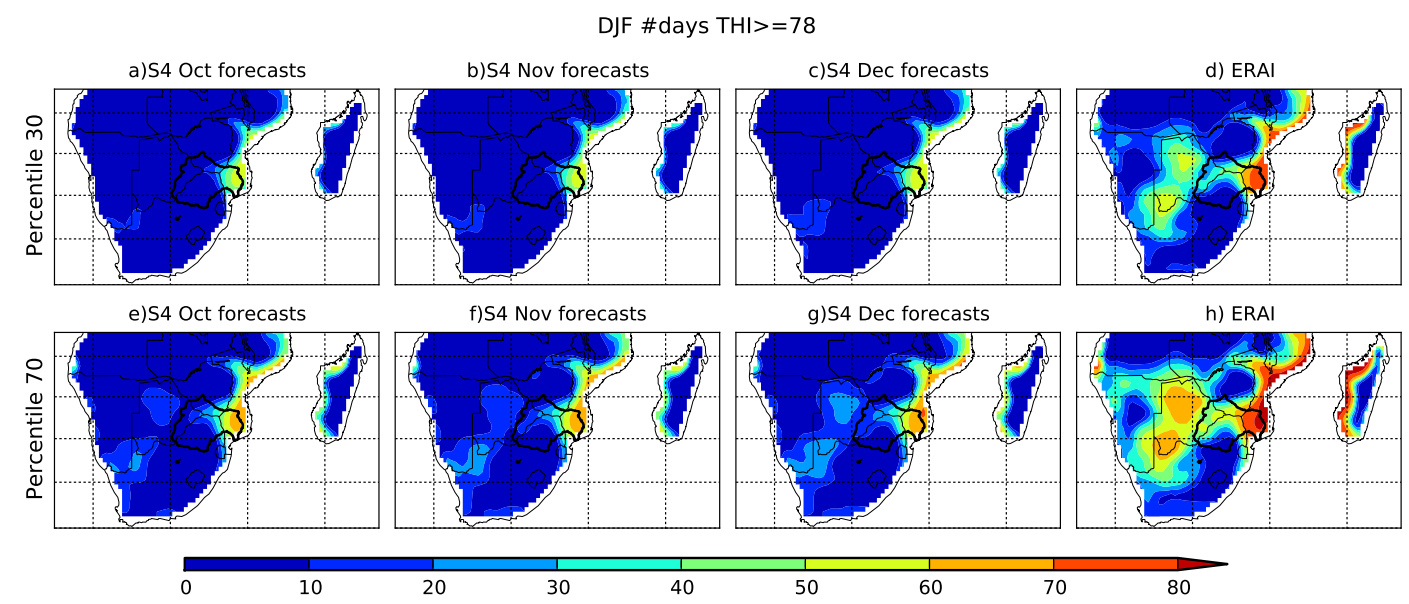

Fig. 5. Same as Fig. 4 but the climatology of DJF frequency of occurrence of days with THI higher than 78.
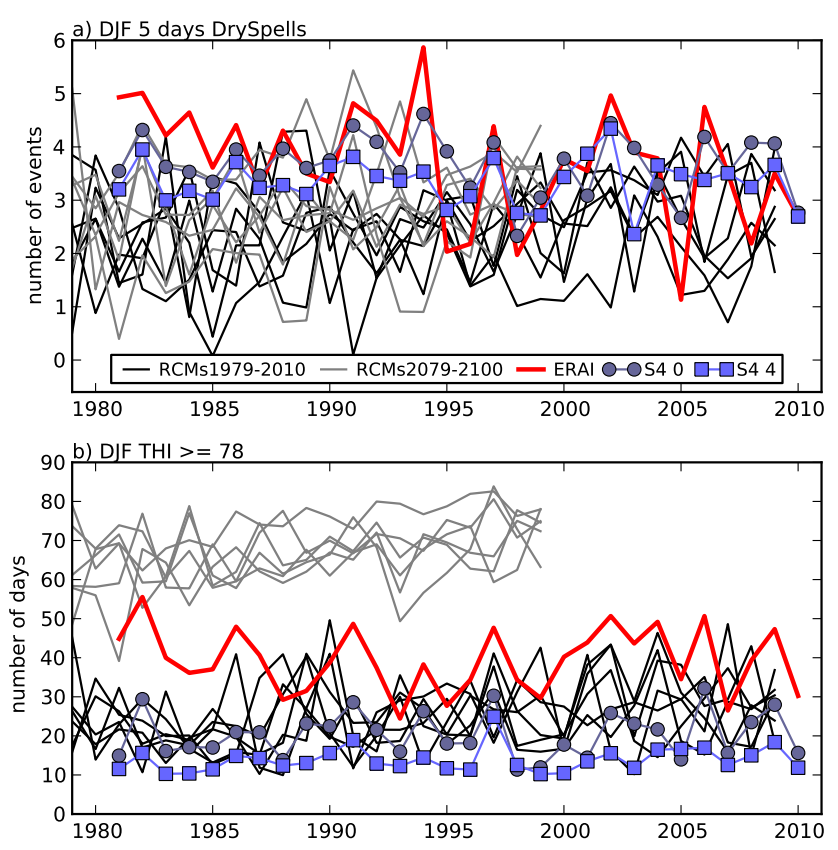

Fig. 6. Time series of the DJF frequency of occurrence of 5-day dry spells (a) and frequency of occurrence of days with THI higher than 78 (b) averaged over the Limpopo region (see basin outline in previous maps). The time series are displayed for ERA-Interim (red line) and ECMWF S4 forecasts initialized in December (0 months lead time - dark blue) and August (4 months lead time - light blue). The black lines display the temporal evolution of the regional climate models between 1979 and 2010 and the gray lines between 2079 and 2100.

\subsubsection{Forecast skill}

Grid-by-grid point correlations (not shown here) indicate that a large fraction of the Limpopo region exhibits significant correlations for all indicators, in particular for the December and November initial forecast dates (i.e. forecasts closest to

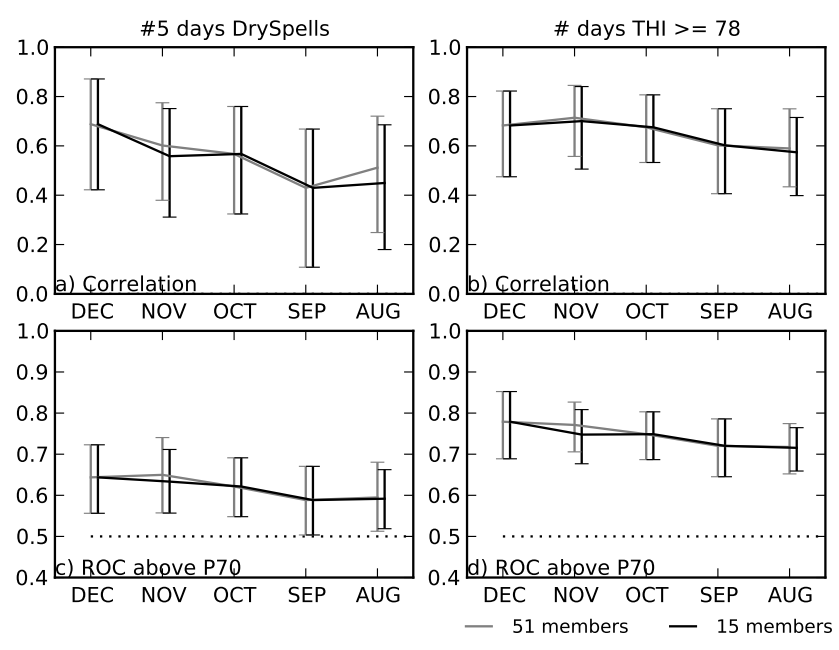

Fig. 7. Seasonal forecast scores over the Limpopo region valid for DJF, at different lead times, for the frequency of occurrence of 5day dry spells (a, c) and frequency of occurrence of days with THI higher than 78 (b, d). Mean grid-point correlation (a, b) and ROC of the forecast anomalies above the upper tercile $(\mathbf{c}, \mathbf{d})$. The error bars denote $95 \%$ confidence intervals estimated from 1000 bootstrap samples. The dark lines show the scores using the 15 ensemble members. The gray lines show the scores when using the full 51 ensemble members in the hindcast period (only available for the November and August initial forecast dates, for the other forecasts, the gray lines show the same as the dark lines).

the DJF season, detailed figures see Supplement). In detail, the THI forecasts show a much higher correlation than the dry spell forecasts. Nevertheless, also the dry spell forecasts reveal correlation, in particular over the Limpopo region and north of the Limpopo (lower Zambezi).

A more detailed analysis of forecast skill was performed over the Limpopo Basin. Figure 7 shows the mean of the grid-point correlation as well as the relative operating characteristic (ROC) scores for above-normal conditions over the 
Limpopo region for each lead time. The 70th percentile is used as the threshold to indicate above-normal conditions. Above-normal conditions in this context means a higher frequency of stress conditions, and is therefore of the most interest to predict with skill. The figures also show the impact of having 15 ensemble members, with respect to 51 ensemble members (dark versus gray lines). This impact is relatively small although with 51 members, the scores are slightly higher. All ROC scores, including normal (between 30th and 70th percentile) and below-normal (below 30th percentile) conditions are also given in Table 1 (dry spells) and Table 2 (THI). The scores show that both indicators have skill (ROC above 0.5). In particular, above-normal conditions of the frequency of days with THI above 78 can be forecast remarkably well by the $\mathrm{S} 4$ forecasts. Tables 1 and 2 also show that it is easier to predict above-normal and below-normal conditions than normal conditions. The ROC scores for normal conditions are clearly lower, sometimes even showing no skill at all (ROC score of 0.5) while above-normal and below-normal can be predicted with similar skill. The large confidence intervals in Fig. 7 and Tables 1 and 2 highlight the temporal sampling uncertainty associated with the small sample size of only 30 seasons.

Figure 8 shows the ROC and reliability (REL) diagrams of the forecast issued in November for above-normal conditions for the frequency of 5-day dry spells and frequency of days with THI higher than 78 . These also confirm the above mentioned differences in skill and the uncertainties due to the temporal sampling. The ROC diagrams are above the oneon-one line for below- and above-normal conditions for both indicators, while they are close to the one-on-one line for normal conditions. The REL diagrams show a remarkable match with the one-on-one line for below- and above-normal conditions, while the REL diagram for normal conditions does not follow the one-on-one line. This shows that for above-normal and below-normal conditions, the frequency distribution of the forecast events is close to the distribution of verified forecast events (REL diagram), and that the forecasts are skilful (ROC diagram).

\section{Discussion}

\subsection{Implications of results}

In this paper, we present forecast skill in the context of climate change to demonstrate if seasonal forecasts may become more important in the future. In this discussion, we treat the two indicators (dry spell frequency and heat stress frequency) in order.

The climate change analysis showed that the heat stress days (THI above 72 for moderate stress and above 78 for severe stress) become much more frequent in the future. These results are confirmed by, for example, Nesamvuni et al. (2012), who also show that very severe stress conditions
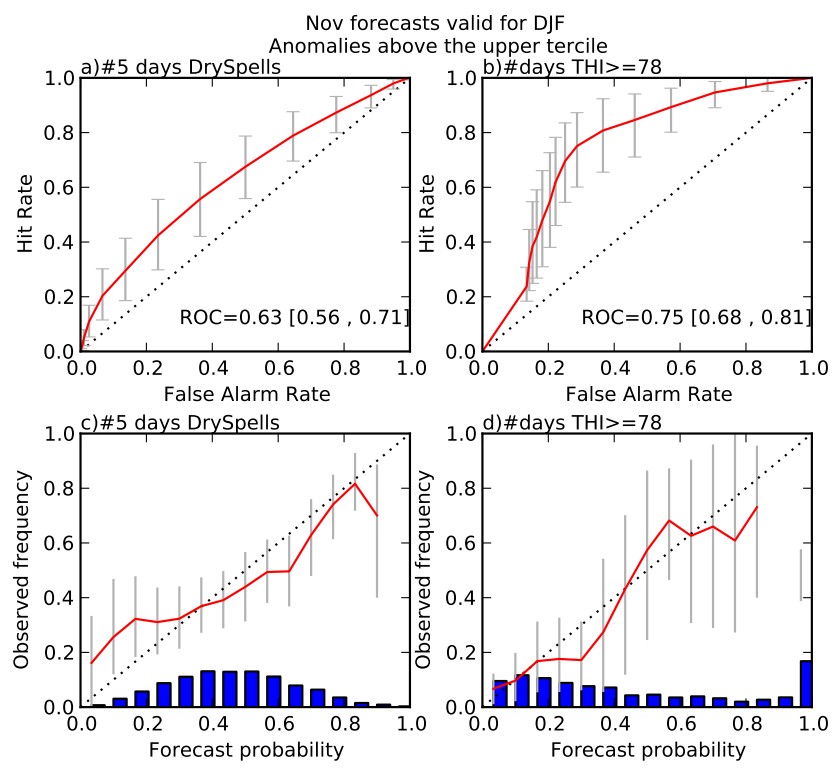

Fig. 8. ROC (a, b) and REL (c, d) diagrams for the forecast anomalies above the upper tercile issued in November and valid for DJF over the Limpopo region: frequency of occurrence for5-day dry spells $(\mathbf{a}, \mathbf{c})$ and frequency of occurrence of days with THI higher than $78(\mathbf{b}, \mathbf{d})$. The gray error bars denote $95 \%$ confidence intervals estimated from 1000 bootstrap samples.

may occur in the distant future within southern Africa. They express the heat stress conditions as mean annual values, while we demonstrate the frequency of occurrence of heat stress days. This indicates that if dairy (and other livestock) farming is to be continued on a large scale across southern Africa, the forecasting of these heat stress days becomes essential and a possible means to adapt to climate change. Fortunately, the skill of predicting such heat stress conditions in the current climate by seasonal forecasts has been demonstrated to be satisfactory for supporting decision-making. In particular, skill for predicting below-normal and abovenormal conditions is good, while skill for predicting normal conditions is low. The fact that heat stress conditions are increasing in frequency in the future and that seasonal forecasts can detect the frequency of occurrence of heat stress conditions skilfully, implies that seasonal forecasts will gain importance for the livestock sector. It should be noted that our best information on heat stress thresholds for livestock (THI higher than 72 and 78, respectively) is provided for cattle. Thresholds for small livestock are subject to future research.

For the frequency of dry spells, although they show some predictability, the increase in importance of forecasts is limited, because their frequency of occurrence does not show increase from the RCM runs used in this study. Moreover, this study demonstrates that the skill of the predictions of dry spell frequency is much lower than the skill of predictions of frequency of heat stress days and that more work is needed 
Table 1. ROC scores over the Limpopo region of the forecast anomalies of 3- and 5-day dry spells above the upper tercile, between the lower and upper terciles (normal) and below the lower tercile during DJF for different initial forecast dates (columns). The values between brackets are estimates of the $\pm 95 \%$ confidence interval from 1000 bootstrap samples. The bootstrapping does not provide exact symmetric confidence intervals around the mean (but they are close to symmetric), but here the average is shown to reduce the amount of data in the table.

\begin{tabular}{lccccc}
\hline \multicolumn{1}{c}{ Dec } & Nov & Oct & Sep & Aug \\
\hline \multicolumn{5}{c}{ Number of 3-day dry spells } \\
\hline Above & $0.61(0.06)$ & $0.55(0.07)$ & $0.58(0.07)$ & $0.56(0.07)$ & $0.57(0.06)$ \\
Normal & $0.52(0.04)$ & $0.50(0.03)$ & $0.48(0.03)$ & $0.52(0.03)$ & $0.50(0.02)$ \\
Below & $0.62(0.06)$ & $0.56(0.07)$ & $0.58(0.08)$ & $0.56(0.07)$ & $0.58(0.07)$ \\
\hline \multicolumn{7}{c}{ Number of 5-day dry spells } \\
Above & $0.64(0.08)$ & $0.63(0.08)$ & $0.62(0.07)$ & $0.59(0.08)$ & $0.59(0.07)$ \\
Normal & $0.56(0.04)$ & $0.47(0.03)$ & $0.52(0.03)$ & $0.53(0.03)$ & $0.54(0.03)$ \\
Below & $0.66(0.09)$ & $0.63(0.08)$ & $0.63(0.07)$ & $0.60(0.08)$ & $0.62(0.08)$ \\
\hline
\end{tabular}

Table 2. As Table 1 but for the number of days with THI $>=72$ and THI $>=78$.

\begin{tabular}{lccccc}
\hline \multicolumn{1}{c}{ Dec } & Nov & Oct & Sep & Aug \\
\hline \multicolumn{5}{c}{ Number of days with THI $>=72$} \\
\hline Above & $0.69(0.08)$ & $0.66(0.08)$ & $0.64(0.07)$ & $0.63(0.10)$ & $0.58(0.09)$ \\
Normal & $0.56(0.07)$ & $0.56(0.06)$ & $0.52(0.05)$ & $0.49(0.05)$ & $0.53(0.04)$ \\
Below & $0.71(0.07)$ & $0.63(0.10)$ & $0.57(0.08)$ & $0.61(0.10)$ & $0.61(0.10)$ \\
\hline \multicolumn{7}{c}{ Number of days with THI $>=78$} \\
Above & $0.78(0.08)$ & $0.75(0.07)$ & $0.75(0.06)$ & $0.72(0.07)$ & $0.72(0.05)$ \\
Normal & $0.61(0.07)$ & $0.56(0.07)$ & $0.57(0.05)$ & $0.53(0.06)$ & $0.56(0.05)$ \\
Below & $0.76(0.08)$ & $0.73(0.08)$ & $0.69(0.07)$ & $0.67(0.08)$ & $0.69(0.06)$ \\
\hline
\end{tabular}

on improvements of precipitation forecasts in order to utilize them in decision-making.

In general, the results show that seasonal forecasts, translated into frequency of occurrence of indicators for critical weather conditions for the agricultural sector, are skilful across southern Africa. In particular, the predictability of the frequency of occurrence of heat stress days expressed in the THI shows good predictability across all lead times considered. The predictability is predominant for below-normal and above-normal conditions. For normal conditions, the skill is much lower. Our analysis discerns itself from other studies by focusing on agricultural indicators (i.e. the frequency of dry spells and THI above thresholds) as meaningful indicators for subsistence farming. We acknowledge that these findings are also relevant to emerging farming, as well as the large-scale commercial farming sectors.

\subsection{Forecast, warning and response chain}

The results of this study show that forecasts of heat stress indicators are skilful, but will also become more important for end users such as farmers or institutions that support farmers in response measures, because their frequency of occurrence will increase in the future. Although these results are promising, we must bear in mind that forecasting is merely one component of the forecasting, warning and response chain (Carsell et al., 2004). If no proper mechanisms for warning are in place, if dissemination does not reach end users in an accessible or appropriate format (Archer, 2003), or no satisfactory mitigation actions or support for such actions are available to the end user, the forecast will still not lead to better preparedness. Furthermore, the real value of the forecast will depend on the amount of misses and false alarms, with respect to the amount of hits, combined with the costs of a wrong forecast, and the benefits of a correct forecast (Verkade and Werner, 2011). To assess the real value, further insight into the costs and benefits of possible decisions, supported by the forecasts, would be needed.

\subsection{Limitations of methods}

The results of this study are subject to a number of assumptions and choices which are discussed in the following subsections. 


\subsubsection{Chosen emission scenario}

First of all, we have currently investigated the IPCC A2 emission scenario. A2 is a high-end emission scenario, which likely results in quite extreme temperature changes. The resulting impacts on critical weather conditions may therefore turn out lower, if other emission scenarios with lower greenhouse gas concentrations are assumed. Further simulations could be done on less extreme emission scenarios and in particular on RCM simulations based on the more recent representative concentration pathways (Van Vuuren et al., 2011).

\subsubsection{Validity of absolute forecast numbers}

We wish to note that the analysis here performed uses a $0.5^{\circ}$ $(\sim 50 \mathrm{~km})$ grid box scale. In addition, the eight surrounding grid boxes are used to build a distribution function of the frequency of occurrence of indicator-threshold combinations. These two factors make the results less representative for a single location. Across one grid box, variability in local climate conditions may occur due to, for example, differences in elevation, vegetation or other climate-influencing factors. To translate the results to local conditions, further downscaling, either statistically or dynamically, is required. We expect that this will not change the overall conclusions of this paper on climate change because such local variability will not impact significantly on the relative change of an indicator in time. However, in areas with highly variable orography, the absolute differences in temperature and rainfall conditions across space may vary significantly. This means that the seasonal forecasts may not fully represent the conditions of a local farmer (i.e. at point scale) and are therefore not ready for use yet. The absence of bias correction in the forecasts also impacts on the absolute accuracy of the forecast. If, however, regional results are to be used for decisionmaking, and anomalies provide enough information to make or change a decision, then our results could already be used. On a local scale, the use of medium-to-monthly range probabilistic forecasts might be more useful for the day-to-day management of resources, as these suffer much less from model drift. The use of medium-to-monthly range forecasts remains, however, outside the scope of this paper.

\subsubsection{Ground truth}

The skill analysis has been performed with a reanalysis data set, rather than ground-truth observations. It is likely that the THI values, computed from the reanalysis, are quite close to ground truth, as the reanalysis data for temperature and dew point temperature are based on data assimilation of ground observations of these variables. Rainfall however, remains a modelled flux and is therefore more strongly conditioned by the ability of the ECMWF model to reproduce rainfall. Therefore, care should be taken that the comparison of the ERA-Interim and forecast climatology of the dry spell frequencies is a model-model comparison, while the THI frequencies are a model-data comparison.

\subsubsection{Forecasting as a climate change adaptation measure}

Throughout this paper we have assumed that if the forecast indicators can be predicted with skill and will occur more frequently in a future climate, the importance of forecasting will increase in the future. In fact, forecasting may be part of an adaptation strategy. Besides forecasting, it is likely that adaptation to climate change will require a larger number of adaptation measures, implemented across different levels within the society. Forecasting is just one such adaptation measure. Nevertheless, even if other adaptation strategies are followed, our analysis demonstrates that forecasts (possibly along with these other measures) will be beneficial to the farmers in the region. For example, if a farmer decides to switch to a more drought-resistant crop due to climatological changes in seasonal rainfall and the frequency of dry spells, the farmer may still benefit from skilful forecasts when a dry condition (e.g. erratic rainfall, or dry spells) is forecast. The farmer may, however, choose a different threshold (e.g. the length of dry spell duration) upon which to act with a mitigation measure during the season.

\subsubsection{Changes in seasonal forecast skill due to climate change}

We have assumed that the skill of the $\mathrm{S} 4$ forecast system does not depend on the climate itself. It could be that the changes in climate in fact also change the predictability properties of the forecasts. For instance, changes in the El Niño-Southern Oscillation (ENSO) may also alter the skill in areas where the climate is dominated by ENSO, because the teleconnections may become stronger or weaker. It is likely that El Niño events will become more frequent and thus predictability will become stronger (IPCC, 2013; Power et al., 2013). Other factors that may impact the forecast skill are, for example, improvements in the physics of the forecast models for ocean circulation, land surface and atmospheric circulation; improvements in resolution; and improving (or deteriorating) observational networks leading to better model initialisation. Nevertheless, we believe that possible changes in the predictability of the events and forecast skill will not change the conclusions of this paper.

\section{Conclusions}

We have investigated whether the importance of seasonal forecasts for smallholder farming will increase over southern Africa and in particular the Limpopo Basin in a changing climate. This has been demonstrated (a) by investigating whether the frequency of occurrence of critical weather conditions for the agricultural sector, in particular rain-fed 
farming and dairy farming, increases in the future according to RCM simulations, and (b) by investigating the skill of seasonal forecasts to detect below-normal, normal or abovenormal frequency of occurrence of these critical weather conditions in the December-February (DJF) season. The focus of critical weather conditions were the DJF frequency of occurrence of dry spells above 3 and 5 days (critical for rainfed agriculture), as well as the DJF frequency of occurrence of temperature heat index values above 72 and 78 (critical for cattle heat stress). If the frequency of occurrence of these indicator-threshold combinations is likely to increase significantly in comparison with current climate; and indicatorthreshold combinations can be forecast with skill, it is likely that seasonal forecasts will gain importance in the future, as they can lead more often to timely decision-making to mitigate the effect of critical weather conditions to the agricultural sector.

From the investigation we can conclude that the seasonal forecasting of dry spells contains skill in particular for forecasts of 1 and 2 months' lead time (and therefore already have potential value to end users). However, they will not gain importance in the future, because the climate change projections used in this study do not show significant increase in their frequency of occurrence. The frequency of heat stress conditions, however, is shown to seriously increase with great certainty in the future and can also be skilfully detected by seasonal forecasts within the DJF season (for all lead times, 1 to 4 months). Both types of indicators show a better skill in predicting above-normal and belownormal conditions than normal conditions. The frequency of heat stress conditions shows more skilful predictions than the skill of predicting frequency of dry spells. Concluding, we can state that in particular the predictions of heat stress conditions already have potential value and will gain importance in the future. In interpreting these results, care should be taken that this study only made limited use of ground observations and that model drift in the seasonal forecasts causes inappropriate absolute values. As a result, only forecasts of anomalies were considered in this study. The climate change projections were based on the SRES A2 scenario, which is a high-end climate scenario. More conservative scenarios may result in less severe increases in heat stress conditions. Although this paper demonstrates skill in predicting critical weather conditions over southern Africa, it is important to note that forecasts alone are not sufficient to alleviate their effects. Sufficient support for mitigation must be in place, and forecasts must be communicated in a context-specific, accessible and understandable format.

\section{Supplementary material related to this article is available online at http://www.hydrol-earth-syst-sci.net/ 18/1525/2014/hess-18-1525-2014-supplement.pdf.}

Acknowledgements. This work has been done in the framework of the EU-FP7 project DEWFORA - Improved Drought Early Warning and FORecasting to strengthen preparedness and adaptation to droughts in Africa. We thank the European Commission Seventh Framework Programme "FP7" for supporting and funding DEWFORA, Grant No. 265454.

Edited by: A. Opere

\section{References}

Archer, E. R. M.: Identifying Underserved End-User Groups in the Provision of Climate Information, B. Am. Meteorol. Soc., 84, 1525-1532, doi:10.1175/BAMS-84-11-1525, 2003.

Archer van Garderen, E. R. M.: (Re) Considering Cattle Farming in Southern Africa under a Changing Climate, Weather. Clim. Soc., 3, 249-253, doi:10.1175/WCAS-D-11-00026.1, 2011.

Barnston, A. G. and Smith, T. M.: Specification and Prediction of Global Surface Temperature and Precipitation from Global SST Using CCA, J. Climate, 9, 2660-2697, doi:10.1175/15200442(1996)009<2660:SAPOGS>2.0.CO;2, 1996.

Barron, J. and Okwach, G.: Run-off water harvesting for dry spell mitigation in maize (Zea mays L.): results from on-farm research in semi-arid Kenya, Agric. Water Manage., 74, 1-21, doi:10.1016/j.agwat.2004.11.002, 2005.

Barron, J., Rockström, J., Gichuki, F., and Hatibu, N.: Dry spell analysis and maize yields for two semi-arid locations in east Africa, Agric. Forest. Meteorol., 117, 23-37, doi:10.1016/S0168-1923(03)00037-6, 2003.

Belo-Pereira, M., Dutra, E., and Viterbo, P.: Evaluation of global precipitation data sets over the Iberian Peninsula, J. Geophys. Res., 116, D20101, doi:10.1029/2010JD015481, 2011.

Brown, C. and Hansen, J.: Agricultural water management and climate risk. Report to the Bill and Melinda Gates Foundation, IRI Tech. Rep. No. 08-01, International Research Institute for Climate mand Society, New York, USA, 2008.

Carsell, K. M., Pingel, N. D. and Ford, D. T.: Quantifying the Benefit of a Flood Warning System, Nat. Hazards Rev., 5, 131-140, doi:10.1061/(ASCE)1527-6988(2004)5:3(131), 2004.

Davis, C.: Climate Risk and Vulnerability: a handbook for southern Africa, Coucil for Scientific and Industrial Research, Pretoria, South Africa., 2011.

Dee, D. P., Uppala, S. M., Simmons, A. J., Berrisford, P., Poli, P., Kobayashi, S., Andrae, U., Balmaseda, M. A., Balsamo, G., Bauer, P., Bechtold, P., Beljaars, A. C. M., van de Berg, L., Bidlot, J., Bormann, N., Delsol, C., Dragani, R., Fuentes, M., Geer, A. J., Haimberger, L., Healy, S. B., Hersbach, H., Hólm, E. V, Isaksen, L., Kållberg, P., Köhler, M., Matricardi, M., McNally, A. P., Monge-Sanz, B. M., Morcrette, J.-J., Park, B.-K., Peubey, C., de Rosnay, P., Tavolato, C., Thépaut, J.-N., and Vitart, F.: The ERA-Interim reanalysis: configuration and performance of the data assimilation system, Q. J. Roy. Meteorol. Soc., 137, 553597, doi:10.1002/qj.828, 2011.

de Groen, M. M. and Savenije, H. H. G.: A monthly interception equation based on the statistical characteristics of daily rainfall, Water Resour. Res., 42, W12417, doi:10.1029/2006WR005013, 2006. 
Dikmen, S. and Hansen, P. J.: Is the temperature-humidity index the best indicator of heat stress in lactating dairy cows in a subtropical environment?, J. Dairy Sci., 92, 109-116, doi:10.3168/jds.2008-1370, 2009.

Dutra, E., Di Giuseppe, F., Wetterhall, F., and Pappenberger, F.: Seasonal forecasts of droughts in African basins using the Standardized Precipitation Index, Hydrol. Earth Syst. Sci., 17, 23592373, doi:10.5194/hess-17-2359-2013, 2013.

Dutra, E., Pozzi, W., Wetterhall, F., Di Giuseppe, F., Magnusson, L., Naumann, G., Barbosa, P., Vogt, J., and Pappenberger, F.: Global meteorological drought - Part 2: Seasonal forecasts, Hydrol. Earth Syst. Sci. Discuss., 11, 919-944, doi:10.5194/hessd11-919-2014, 2014.

Engelbrecht, C. J., Engelbrecht, F. A., and Dyson, L. L.: Highresolution model-projected changes in mid-tropospheric closedlows and extreme rainfall events over southern Africa, Int. J. Climatol., 33, 173-187, doi:10.1002/joc.3420, 2013.

Engelbrecht, F. A., McGregor, J. L., and Engelbrecht, C. J.: Dynamics of the Conformal-Cubic Atmospheric Model projected climate-change signal over southern Africa, Int. J. Climatol., 29, 1013-1033, doi:10.1002/joc.1742, 2009.

Engelbrecht, F. A., Landman, W. A., Engelbrecht, C. J., Landman, S., Bopape, M. M., Roux, B., McGregor, J. L., and Thatcher, M.: Multi-scale climate modelling over Southern Africa using a variable-resolution global model, Water SA, 37, 647-658, 2011.

Gerrits, A. M. J., Savenije, H. H. G., Hoffmann, L., and Pfister, L.: New technique to measure forest floor interception - an application in a beech forest in Luxembourg, Hydrol. Earth Syst. Sci., 11, 695-701, doi:10.5194/hess-11-695-2007, 2007.

Hetem, R. S., de Witt, B. A., Fick, L. G., Fuller, A., Maloney, S. K., Meyer, L. C. R., Mitchell, D., and Kerley, G. I. H.: Effects of desertification on the body temperature, activity and water turnover of Angora goats, J. Arid Environ., 75, 20-28, doi:10.1016/j.jaridenv.2010.08.007, 2011.

Ingram, K., Roncoli, M., and Kirshen, P.: Opportunities and constraints for farmers of west Africa to use seasonal precipitation forecasts with Burkina Faso as a case study, Agric. Syst., 74, 331-349, doi:10.1016/S0308-521X(02)00044-6, 2002.

IPCC: Summary for Policymakers, Climate Change 2013: The Physical Science Basis. Contribution of Working Group I to the Fifth Assessment Report of the Intergovern- mental Panel on Climate Change, Cambridge, available from: https://www.ipcc.ch/ report/ar5/wg1/ (last access: 19 March 2014), 2013.

Kane, R. P.: Periodicities, ENSO effects and trends of some South African rainfall series: an update, S. Afr. J. Sci., 105, 199-207, 2009.

Kusangaya, S., Warburton, M. L., Archer van Garderen, E., and Jewitt, G. P. W.: Impacts of climate change on water resources in southern Africa: A review, Phys. Chem. Earth A/B/C, doi:10.1016/j.pce.2013.09.014, in press, 2013.

Lal, M., McGregor, J. L., and Nguyen, K. C.: Very high-resolution climate simulation over Fiji using a global variable-resolution model, Clim. Dynam., 30, 293-305, doi:10.1007/s00382-0070287-0, 2008.

Landman, W. A., Engelbrecht, F. A., Beraki, A., Engelbrecht, C., Mbedzi, M., Gill, T., and Ntsangwane, L.: Model output statistics applied to multi-model ensemble long-range forecasts over South Africa, Project Report, Water Research Commission, Pretoria, South Africa, 2009.
LIMCOM: Joint Limpopo River Basin Study Scoping Phase: Final Report, Republica de Mocambique, Ministerio Das Obras Publicas e Habitacao - Direccao Nacional De Aguas/Limpopo Basin Permanent Technical Committee, Mozambique, 2010.

Love, D., Uhlenbrook, S., Twomlow, S., and Van der Zaag, P.: Changing hydroclimatic and discharge patterns in the northern Limpopo basin, Zimbabwe, Water SA, 36, 335-350, 2010.

Malherbe, J., Engelbrecht, F. A., and Landman, W. A.: Projected changes in tropical cyclone climatology and landfall in the Southwest Indian Ocean region under enhanced anthropogenic forcing, Clim. Dynam., 40, 2867-2886, doi:10.1007/s00382012-1635-2, 2013.

McGregor, J. L.: C-CAM geometric aspects and dynamical formulation, in: CSIRO Atmospheric Research Technical paper, vol. 70, CSIRO Atmospheric Research, Aspendale, Vic., Australia, 2005.

McGregor, J. L. and Dix, M. R.: An Updated Description of the Conformal-Cubic Atmospheric Model, in: High Resolution Numerical Modelling of the Atmosphere and Ocean, edited by: Hamilton, K. and Ohfuchi, W., Springer, New York , 51-75, 2008.

Mitchell, T. D. and Jones, P. D.: An improved method of constructing a database of monthly climate observations and associated high-resolution grids, Int. J. Climatol., 25, 693-712, doi:10.1002/joc.1181, 2005.

Molteni, F., Stockdale, T., Balsameda, M., Balsamo, G., Buizza, R., Ferranti, L., Magnusson, L., Mogensen, K., Palmer, T., and Vitart, F.: The new ECMWF seasonal forecast system (System 4), ECMWF Tech. Memo 656, ECMWF, Reading, UK, 2011.

Mwangi, E., Wetterhall, F., Dutra, E., Di Giuseppe, F., and Pappenberger, F.: Forecasting droughts in East Africa, Hydrol. Earth Syst. Sci., 18, 611-620, doi:10.5194/hess-18-611-2014, 2014.

Nardone, A., Ronchi, B., Lacetera, N., Ranieri, M. S., and Bernabucci, U.: Effects of climate changes on animal production and sustainability of livestock systems, Livest. Sci., 130, 57-69, doi:10.1016/j.livsci.2010.02.011, 2010.

Nesamvuni, E., Lekalakala, R., Norris, D., and Ngambi, J. W.: Effects of climate change on dairy cattle, South Africa, Afr. J. Agric. Res., 7, 3867-3872, doi:10.5897/AJAR11.1468, 2012.

Nunez, M. and McGregor, J. L.: Modelling future water environments of Tasmania, Australia, Clim. Res., 34, 25-37, doi:10.3354/cr034025, 2007.

Nyakudya, I. W. and Stroosnijder, L.: Water management options based on rainfall analysis for rainfed maize (Zea mays L.) production in Rushinga district, Zimbabwe, Agric. Water Manage., 98, 1649-1659, doi:10.1016/j.agwat.2011.06.002, 2011.

O'brien, S. P.: Anticipating the Good, the Bad, and the Ugly An Early Warning Approach to Conflict and Instability Analysis, J. Conflict Resolut., 46, 791-811, doi:10.1177/002200202237929, 2002.

Ochola, W. O. and Kerkides, P.: A Markov chain simulation model for predicting critical wet and dry spells in Kenya: analysing rainfall events in the Kano Plains, Irrig. Drain., 52, 327-342, doi:10.1002/ird.94, 2003.

Parr, J. F., Stewart, B. A., Hornick, S. B., and Singh, R. P.: Improving the Sustainability of Dryland Farming Systems: A Global Perspective, in: Advances in Soil Science, edited by: Singh, R. P., Parr, J. F., and Stewart, B. A., Springer, New York, 1-8, 1990. 
Power, S., Delage, F., Chung, C., Kociuba, G., and Keay, K.: Robust twenty-first-century projections of El Niño and related precipitation variability, Nature, 502, 541-545, doi:10.1038/nature12580, 2013.

Ramos, M.-H., Mathevet, T., Thielen, J., and Pappenberger, F.: Communicating uncertainty in hydro-meteorological forecasts: mission impossible?, Meteorol. Appl., 17, 223-235, doi:10.1002/met.202, 2010.

Ramos, M. H., van Andel, S. J., and Pappenberger, F.: Do probabilistic forecasts lead to better decisions?, Hydrol. Earth Syst. Sci., 17, 2219-2232, doi:10.5194/hess-17-2219-2013, 2013.

Ravagnolo, O., Misztal, I., and Hoogenboom, G.: Genetic Component of Heat Stress in Dairy Cattle, Development of Heat Index Function, J. Dairy Sci., 83, 2120-2125, doi:10.3168/jds.S00220302(00)75094-6, 2000.

Reason, C. J. C., Hachigonta, S., and Phaladi, R. F.: Interannual variability in rainy season characteristics over the Limpopo region of southern Africa, Int. J. Climatol., 25, 1835-1853, doi:10.1002/joc.1228, 2005.

Rockström, J.: Water resources management in smallholder farms in Eastern and Southern Africa: An overview, Phys. Chem. Earth B, 25, 275-283, doi:10.1016/S1464-1909(00)00015-0, 2000.

Rockström, J.: Water for food and nature in drought-prone tropics: vapour shift in rain-fed agriculture, Philos. T. R. Soc. Lond. B, 358, 1997-2009, doi:10.1098/rstb.2003.1400, 2003.

RVAC: SADC Regional Vulnerability Assessment and Analysis (RVAA) Synthesis Report: State of Food Insecurity and Vulnerability in the Southern Africa Development Community, RVAA Annual Dissemination Forum, Johannesburg, South Africa, 2011.
Savenije, H. H. G.: The importance of interception and why we should delete the term evapotranspiration from our vocabulary, Hydrol. Process., 18, 1507-1511, doi:10.1002/hyp.5563, 2004.

Usman, M. T. and Reason, C. J. C.: Dry spell frequencies and their variability over southern Africa, Clim. Res., 26, 199-211, doi:10.3354/cr026199, 2004.

Van Vuuren, D. P., Edmonds, J., Kainuma, M., Riahi, K., Thomson, A., Hibbard, K., Hurtt, G. C., Kram, T., Krey, V., Lamarque, J.F., Masui, T., Meinshausen, M., Nakicenovic, N., Smith, S. J., and Rose, S. K.: The representative concentration pathways: an overview, Climatic Change, 109, 5-31, doi:10.1007/s10584-0110148-z, 2011.

Verkade, J. S. and Werner, M. G. F.: Estimating the benefits of single value and probability forecasting for flood warning, Hydrol. Earth Syst. Sci., 15, 3751-3765, doi:10.5194/hess-15-37512011, 2011.

Wetterhall, F., Winsemius, H. C., Dutra, E., Werner, M., and Pappenberger, F.: Seasonal predictions of agro-meteorological drought indicators for the Limpopo basin, Hydrol. Earth Syst. Sci. Discuss., 11, 861-888, doi:10.5194/hessd-11-861-2014, 2014.

Ziervogel, G., Archer van Garderen, E., Midgley, G., Hamann, R., Taylor, A., Stuart-Hill, S., Warburton-Toucher, M., and Myers, J.: Climate change impacts and adaptation in South Africa: current approaches and future challenges, WiRES Clim. Chang., in revision, 2014. 